\title{
Fusion of mental health and incapacity legislation
}

\author{
JOHN DAWSON and GEORGE SZMUKLER
}

\begin{abstract}
Summary The enactment of a single legislative scheme governing nonconsensual treatment of both 'physical' and 'mental' illnesses, based on incapacity principles, has been mooted in recent law reform debates in the UK. We propose a framework for such legislation and consider in more detail the provisions it should contain. The design of legislation that combines the strengths of both incapacity and civil commitment schemes can be readily imagined, based on the criteria for intervention in England and Wales found in the Mental Capacity Act 2005. Such legislation would reduce unjustified legal discrimination against mentally disordered persons and apply consistent ethical principles across medical law.
\end{abstract}

\section{Declaration of interest None. \\ Funding detailed in Acknowledgement.}

Why should separate statutes govern the involuntary treatment of 'physical' and 'mental' illness? Why not bring all involuntary treatment under a single statutory scheme? The principal justification for all treatment without consent could then be incapacity to make necessary treatment decisions. Flexible procedures could be followed, albeit with some common elements, and all compulsory treatment could be supervised under one administrative scheme. It is not hard to imagine such legislation. Its development was hinted at in the UK law reform process (Richardson, 1999; Millan, 2001), even as proposals for new incapacity and reformed mental health legislation were developed, simultaneously, on largely separate paths. Each regime has its particular strengths. In this special article we advocate fusion of the two schemes into a comprehensive involuntary treatment statute and consider in more depth the legal provisions it should contain.

\section{PURPOSES}

In designing a comprehensive involuntary treatment statute, we must consider initially the purposes it would serve. One major aim of bringing all involuntary treatment under a single legislative scheme is to avoid discrimination against people with mental disorders (and, perhaps, against mental health professionals) by not making psychiatric treatment, unnecessarily, the subject of special legislation. Using a single scheme acknowledges the problematic character of the distinction between 'mental' and 'physical' illness; it confirms that mental disorder is not invariably associated with loss of decision-making capacity; and it recognises that there are many general medical patients who lack capacity (Raymont $e t$ al, 2004), some of whom actively object to intervention, with just as serious consequences for their health as refusal of psychiatric care. Management of this latter group of patients can be particularly problematic as little guidance on the proper use of force is currently provided by the law. Relying on a single legislative scheme would also avoid the need to define the complex boundaries between the spheres of operation of two distinct (but closely related) schemes (Joint Committee on the Draft Mental Health Bill, 2005: chapter 4).

Under a comprehensive statute, the decision-making incapacity of the patient would be the central criterion for involuntary treatment in all medical contexts. It would replace the twin criteria of mental disorder and risk of harm (to self or others, including serious risks to health) that currently justify involuntary treatment under the Mental Health Act 1983 in England and Wales. Adoption of a uniform standard would reflect the central role of autonomy and incapacity principles in contemporary medical ethics and the fact that non-psychiatric treatment, even of mentally disordered persons, is now covered by incapacity principles under general medical law.

To our knowledge, no clear case has been made that impairment of patients' capacity differs in any essential respect in mental and physical disorders. In both cases, some impairment or disturbance of mental functioning is the cause of the patient's incapacity, and legal criteria sufficiently inclusive to cover the full range of situations can be devised (Grisso \& Appelbaum, 1998). These general incapacity criteria could be at least as satisfactory as the Mental Health Act 1983 criteria for detaining patients, which present their own problems of definition and application (Dawson, 1996; Peay, 2003). Reliance on incapacity criteria would shift the focus away from potential 'risk of harm' as the central ground upon which psychiatric treatment may be imposed. This shift is likely to have two main consequences. First, it might permit earlier intervention, in both physical and mental illness, because intervention would be authorised as soon as the patient lacked capacity to determine treatment, whether or not there was an imminent threat of harm. That approach is likely to find support with many patients' families. Second, reliance on incapacity criteria would permit uniform application of the criminal law: those who harmed others - or attempted to do so - could be controlled through the criminal justice system if they retained capacity, whether mentally disordered or not; whereas those who lacked capacity could be managed under comprehensive involuntary treatment legislation, whether 'dangerous' or not. Mentally disordered persons would no longer be subject to a special form of preventive intervention on the basis of 'risk of harm' regardless of their capacity, while members of other groups who may cause more harm (such as violent behaviour by people with substance use disorders) cannot be controlled until they breach the criminal law.

The general purpose of the fusion proposal, then, is to reduce discrimination and apply consistent ethical principles across medical law. In our attempt to consider the detailed design of a comprehensive involuntary treatment statute, we have examined the distinct functions commonly performed by incapacity (or adult 
guardianship) legislation on the one hand, and mental health (or civil commitment) legislation on the other, bearing in mind that considerable variations exist in such schemes within the common law world. We have also considered the relevance of mental health legislation to some decisions taken in the criminal justice system and within forensic care, and have considered several objections to the fusion proposal and whether, in response, some departure from pure incapacity principles is required.

\section{USUAL FEATURES OF INCAPACITY AND CIVIL COMMITMENT SCHEMES}

\section{Incapacity schemes}

Where a dispute exists concerning the non-consensual treatment of an adult, incapacity legislation typically requires an application to be made to a court (or tribunal) for a determination that the person concerned lacks the capacity to make certain decisions about his or her own treatment or care. Then, if that ruling is made, two main avenues are usually open to the court: to make the relevant decisions itself, directing residential care or authorising treatment, for example, or to appoint another adult as a substitute decision-maker for the person concerned. Substitute decision-makers will usually be required to act in the 'best interests' of those they represent, to take into account their prior wishes or values, and to consult with others about their care. Review and accountability mechanisms will be provided, and some highly sensitive decisions (such as consent to abortion) may be put wholly beyond the decision-maker's powers.

Three main models of substitute decision-making are available. Under a 'private' model, a family member or friend is appointed to act for the incapacitated person; under a 'public' model, the person appointed is the holder of a public office, such as a public guardian or one of their employees; and under a 'clinical' model, the decision-maker is a designated member of the treatment team. The choice from among these options may significantly affect the treatment approval process.

Some incapacity schemes go further, to specify the legal effect of any advance directive about treatment issued by a capable person who later loses capacity, or to authorise the execution of an enduring power of attorney for healthcare, through which a capable person may nominate a preferred substitute decision-maker in advance. In addition, the Mental Capacity Act 2005 for England and Wales takes the unusual step of declaring certain 'acts in connection with care or treatment' to be lawful (section 5) that have previously been justified under the common law ( $\mathrm{R} v$. Bournewood Community and Mental Health NHS Trust, 1998). Generally speaking, these are actions taken when there are reasonable grounds to believe a person lacks the capacity to consent, and the actions taken would be in that person's best interests and would not constitute a deprivation of the person's liberty within the meaning of the European Convention on Human Rights.

Incapacity legislation can achieve these kinds of aims without making any express reference to mental disorder or other causes of incapacity. Instead, it can focus on the particular abilities a person must demonstrate (such as understanding and foreseeing the consequences of treatment) for others to accept the validity of the person's decisions. Where these abilities are lacking, the person may be considered incapacitated regardless of cause.

Many important matters may still be left unspecified. Not all incapacity schemes cover the emergency treatment of an incapacitated person before the consent of the substitute decision-maker has been obtained, and not all questions may be resolved concerning the restraint or confinement of incapacitated persons or concerning the position of third parties who act in reliance on the substitute decisionmaker's powers.

\section{Civil commitment schemes}

In contrast to the above, matters of detention and emergency treatment in the case of mentally disordered persons are the central focus of civil commitment schemes. In these areas the mental health legislation will contain a detailed code of rules. Police intervention, emergency admission to psychiatric care and immediate treatment at the discretion of clinicians will usually be expressly authorised, but only in specified circumstances, and only for those found mentally disordered under the Act. Even then, only psychiatric treatment will be authorised. Other treatments (such as general surgery) will be covered by the incapacity legislation or by general principles of medical law.
Civil commitment legislation therefore authorises emergency detention before any opportunity exists for the person's incapacity to be adjudicated by a court. Intervention can occur at considerable speed and significant discretion to authorise urgent treatment is usually left in clinicians' hands. Committed patients may then be detained under this scheme - even in secure conditions - for lengthy periods. Nevertheless, there may be no express requirement in such mental health legislation for the capacity of involuntary patients to be assessed whenever treatment is proposed. With some limited exceptions, under the law in Britain and Australasia committal under mental health legislation deprives patients of their usual right to refuse psychiatric treatment, regardless of their capacity, until they are discharged from the involuntary treatment scheme. Further, under the law in those countries, authority over the psychiatric treatment of committed patients is not usually transferred to family members, or to other substitute decision-makers drawn from separate public agencies. Families may need to be consulted about treatment, and they may have other entitlements, such as the nearest relative's power to discharge the patient from treatment. Nevertheless, the principal authority to direct psychiatric treatment of committed patients usually lies with responsible clinicians, even if second opinions - or mandatory peer review of the treatment they recommend - are also required. A 'clinical' model of substitute decision-making dominates, with dynamics different from the 'private' or 'public' models more typical of incapacity schemes.

A final feature of mental health legislation is its relevance to the criminal justice system and to forensic care. The criteria in the mental health legislation for involuntary treatment are usually applied to prisoners transferred to psychiatric care; to the making of hospital orders by criminal courts, which authorise treatment without consent; to the position of persons found not guilty by reason of insanity or unfit to stand trial who are reclassified to civil status; and to the treatment of forensic patients generally. In all these situations, rules drawn from the Mental Health Act 1983 are frequently applied.

The general effect of civil commitment legislation is, therefore, that the authority of psychiatrists to detain and treat involuntary psychiatric patients is more clearly established than with other forms of 
medical care. Use of these powers is more heavily regulated as a consequence, with more intensive and frequent review procedures the norm.

\section{CENTR AL FEATURES OF AN INVOLUNTARY TREATMENT STATUTE}

We now consider the best way to fuse the diverse elements of typical incapacity and mental health legislation into one comprehensive regime. This regime would cover those with either 'mental' or 'physical' disorders who lack capacity but object to treatment, an occurrence more common in those with mental illness, but not restricted to their situation.

\section{Criteria for intervention}

The basic criteria for all interventions under the new statute could be stated through a general definition of personal decision-making incapacity. The incapacity criteria need not be linked to any specific illness or disabling condition, but should be sufficiently flexible to accommodate the complex and subtle kinds of incapacity found in some people with serious but intermittent mental disorders (as proposed by Grisso \& Appelbaum, 1998).

If detention of a person is to be authorised for treatment purposes on the foundation of such criteria, care must be taken to comply with the European Convention on Human Rights (in countries party to it) as to the circumstances in which detention of a person may lawfully occur. The Convention does not explicitly authorise detention based on general incapacity criteria. What it does authorise, of most relevance here, is the lawful detention of 'persons of unsound mind' (Article 5(e)) (HL $v$. The United Kingdom, 2004). To ensure that any detention of a person authorised by comprehensive incapacity legislation would be fully compatible with that article, it might be necessary to include some reference to unsoundness of mind (or an equivalent concept), as the cause of incapacity, in the text of the law.

The Mental Capacity Act 2005 illustrates the point. Section 2(1) expressly requires that the person's incapacity be related to 'an impairment of, or disturbance in the functioning of, the mind or brain'. That should be sufficient to bring a person's detention under that regime within the 'unsound mind' requirement of European human rights law. As to the definition of incapacity itself, we see no reason why the carefully drafted criteria found in the Mental Capacity Act 2005 could not provide the basic standards for all intervention under a comprehensive involuntary treatment statute. Section 3 defines decisionmaking capacity by reference to a person's ability to understand and retain relevant information, to use or weigh that information in the decision-making process, and to communicate the decisions made.

\section{Emergency treatment and assessment}

In the early stages of any intervention for emergency treatment, before the person concerned can be fully assessed, the presence of 'reasonable grounds to believe' that the person lacks the capacity to make treatment decisions should be sufficient to set the involuntary assessment process in motion. A comprehensive regime should then provide designated classes of professionals (including, in some cases, the police) with express powers to intervene when an apparently incapacitated person refuses necessary treatment and no less-restrictive option is available to resolve the situation satisfactorily. As under the Mental Health Act 1983, powers of entry, apprehension and transportation of the person to an examination would be required. The Act would then authorise a staggered process of involuntary assessment, requiring personal examination of the individual at designated intervals by appropriate specialists. During that process, provision of immediately necessary treatment by responsible clinicians would be allowed.

Further decisions would then be required concerning the location of the person's continuing treatment and whether detention is necessary. Different forms of treatment, at different locations and under different conditions, would be authorised, and no sharp distinction need be made in the law between treatment for mental and physical conditions, or between inpatient and out-patient care. Community treatment orders would be a possible option for those who lacked capacity but could be treated effectively outside hospital.

Following the decision of the European Court of Human Rights in HL $v$. The United Kingdom (2004), the legislation should also provide some procedural safeguards for non-objecting but incapacitated patients, when restrictions on their liberty, exercised during their care, are of such a 'degree and intensity' as to constitute 'deprivation of liberty' within the meaning of the European Convention. That is likely to be the case whenever public sector health professionals exercise 'complete and effective control' over the patient's care and movement, whether or not the patient is held behind locked doors (HL $v$. The United Kingdom, 2004). In our view, the scope of such extra protections should depend largely on the incapacity and vulnerability of the persons concerned, not on the distinction between psychiatric and general medical care. Those extra safeguards could lie somewhere between those provided for non-objecting patients, who are not effectively detained, and those for patients who object.

Every person under involuntary assessment should have swift access to rights advice, to legal aid and to a hearing before a court or tribunal to contest the legality of continuing intervention in that person's life. There could be early access to a court or tribunal on request, followed by a mandatory hearing under conditions of full procedural fairness within a reasonable time. Any supervisory body (like the current Mental Act Commission) should have jurisdiction over all persons under the statutory scheme.

\section{Involuntary treatment}

Once the initial assessment had been completed, which might take several weeks, the court (or a health tribunal, similar to tribunals under the Mental Health Act 1983) should rule whether any further treatment against the patient's objections may proceed. A range of court orders could then be made. The appropriate substitute decision-maker for the patient could be determined from a range of alternatives, including the option of the responsible clinician. Any special parameters could be set within which substitute treatment decisions should be made. For example, if the decision-maker were not a member of the person's family, mandatory consultation with the family (and others) could still be required. The intensity of the subsequent review procedures and the duration of the treatment order could be specified by the court; alternatively, several pathways of review and accountability could be specified by the legislation, between which the court would choose. In effect, a range of involuntary treatment 'menus' would apply. 
If further legal conditions were to be imposed on especially intrusive forms of treatment, akin to the requirement of a second opinion for some treatments under the Mental Health Act 1983, those conditions should apply to all treatments of a similarly intrusive kind, not just to mental healthcare. We see no good reason for special legal rules to apply when incapacitated patients are prescribed psychotropic medication, for example, when similar rules would not apply to intrusive forms of general medical care such as surgery. Finally, the statute should specify the effect within this involuntary treatment process of any clearly expressed prior views of the patient concerning his or her future healthcare, and of any prior appointment of an enduring attorney for healthcare.

In total, these principles would provide a sound structure for a comprehensive involuntary treatment scheme. There are still principled objections that can be raised to this proposal, of course. Two are considered below. These concern potential difficulties in assessing the capacity of mentally disordered persons to consent to psychiatric care, and potential difficulties in relying on incapacity criteria in the special context of forensic care.

\section{INCAPACITY AND MENTAL DISORDER}

As in many jurisdictions, in England and Wales there are already many situations in which the capacity of mentally disordered persons must be assessed for particular legal purposes, whether or not those persons would be covered by the criteria of mental disorder in the Mental Health Act 1983. Their capacity to consent to general medical care, make a will, enter a contract, vote, stand trial and so on, may all require specific evaluation, quite independently of the Mental Health Act (British Medical Association \& The Law Society, 2004). Such particularised assessments will become even more frequent under the Mental Capacity Act 2005.

Assessing capacity is still a complicated matter. It involves several related steps: setting the criteria of capacity, including the specific domains in which it will be assessed; evaluating performance in those domains; then reaching a judgement whether the person's performance meets the criteria set. In Grisso \& Appelbaum's terms, it involves a 'person $\times$ task $\times$ context $\times$ consequences' analysis, which requires 'special skills' (Grisso \& Appelbaum, 1998: p. 77). Full documentation of this assessment process may impose significant burdens on clinicians. These are all general difficulties, however. They apply right across the capacity assessment field. The existence of such general difficulties cannot explain why the law should require the capacity of mentally disordered persons to be specifically assessed in many particular contexts, but not in the context of consent to mental healthcare. Assessing a mentally disordered person's capacity to consent to amputation of a leg, for example (In re C, 1994) may be just as difficult as assessing the person's capacity to consent to electroconvulsive therapy, but only the latter treatment is covered by the Mental Health Act 1983. In any case, assessing the severity of a person's mental disorder, or conducting 'risk assessment' calculations, may be just as complex.

It may still be said that assessing the capacity of mentally disordered persons to consent to psychiatric treatment presents particular difficulties. Attention may be directed to the lack of training in capacity assessment of many relevant professionals involved in the civil commitment process; to the common need to assess mentally disordered persons in emergency circumstances, on the basis of very limited information; and to the special features of some mental conditions, such as subtle delusions, the denial of illness and rapidly fluctuating course. These difficulties may suggest that a statutory definition of mental disorder typical of mental health legislation could be applied more reliably in such circumstances than a general incapacity test.

If capacity assessment in those circumstances was particularly unreliable (or inconsistent), it might be incompatible with constitutional and human rights principles prohibiting arbitrary interference with personal liberty. As article 9(1) of the International Covenant on Civil and Political Rights states, 'No one shall be subjected to arbitrary arrest or detention' (United Nations, 1966). A test of incapacity so vague, or so difficult to apply in the circumstances typical of civil commitment, that it produced poor interrater reliability might permit arbitrary decisions to be made about detention in mental health facilities contrary to human rights norms. Excessively vague civil commitment criteria are also vulnerable on this ground, but the problem may be compounded when we abandon 'mental disorder' altogether as the principal standard governing detention in mental health facilities, in favour of a general incapacity test.

At present, research evidence to help resolve this kind of controversy is just beginning to appear. There is evidence that modestly trained medical capacity assessors can reach adequate to high levels of interrater reliability in hospital settings, even concerning the psychiatric treatment decisions of mentally disordered persons (Grisso \& Appelbaum, 1998; Cairns et al, 2005); but there is no evidence concerning the reliability of capacity assessments conducted in the emergency settings typical of civil commitment, nor concerning capacity assessment by non-medical professionals, such as the police or approved social workers, who apply the Mental Health Act 1983 criteria at the initial stage. On the other hand, there is no more research evidence concerning the interrater reliability of decisions to detain patients under the Mental Health Act 1983. It is likely that significant variations in practice occur, between clinicians, hospitals and regions (Peay, 2003; Perkins, 2003), particularly with patients having a primary diagnosis of personality disorder. The definitions of mental disorder found in mental health legislation are often pitched in very general terms. No further definition is provided for the critical term 'mental illness' in the Mental Health Act 1983, and the Draft Mental Health Bill for England and Wales (Department of Health, 2004) relies heavily on the term 'mental disorder', which is simply said to mean 'an impairment of or a disturbance in the functioning of the mind or brain resulting from any disability or disorder of the mind or brain' (Department of Health, 2004: clause 2(5)). All definitions of incapacity and mental disorder encounter hard cases at the margins.

More precise definitions of mental disorder can be included in the law. The Butler Committee advocated a legal definition based on discrete forms of psychopathology, such as delusions, severe disorders of mood and perception, and grossly disordered thought process (Home Office \& Department of Health and Social Security, 1975). The clarification of such specialised terminology has received enormous emphasis in psychiatry. The most appropriate comparison, therefore, may be between the reliability of applying mental health legislation that includes a well-crafted definition of mental 
disorder, and the reliability of applying well-constructed incapacity standards such as those found in the Mental Capacity Act 2005.

Whether one set of standards could then be applied more reliably than the other, after the professionals concerned had been properly trained, reducing the possibility of arbitrary intervention in people's lives, would be an interesting focus for research. To be fully convincing, that research would have to be conducted across the full range of settings in which civil commitment decisions occur.

The 'dilemma of denial' of mental illness (Roth et al, 1982) and the fluctuating course of some mental disorders may still present special problems in assessing capacity to consent to psychiatric care. How much insight, or understanding of their illness, and of the consequences of not treating it, should depressed or deluded patients demonstrate for their treatment choices to be respected? To address such questions, the domain of 'appreciation' of illness is often included in capacity tests for mental healthcare (Grisso \& Appelbaum, 1998). The Mental Capacity Act 2005 arguably covers similar ground when it refers to a person's ability to 'use or weigh' information 'as part of the process of making the decision' (section 3(1)(c)), as that ability may be compromised when a person fails to appreciate the seriousness of his or her condition. Nevertheless, express reference to people's ability to 'appreciate' their position may still be useful in a capacity test applicable to mental healthcare.

Similarly, the dilemma posed by patients with fluctuating mental conditions who temporarily regain their capacity after medication, and again refuse necessary treatment, could be specifically addressed in the law. Where the patient has been treated involuntarily on several occasions with a positive response, and a sustained course of treatment is again considered necessary, sustained resumption of capacity on the part of the patient might be required for the patient's refusal to be honoured. Or, to put the matter another way, only 'substantially diminished capacity' to consent might be required for such treatment to proceed (Millan, 2001). That might be the kind of test applied now by tribunals when considering the discharge of patients from the Mental Health Act 1983 who would not be freshly placed under the Act in their current condition (Peay, 1989; Perkins, 2003). General incapacity criteria might address these issues satisfactorily, but they would have to be drafted in sufficiently inclusive terms.

\section{INCAPACITY AND FORENSIC CARE}

Finally, we must consider the consequences of relying on incapacity criteria in the special context of forensic care. The Mental Health Act 1983 criteria for compulsory treatment (based on a definition of mental disorder rather than incapacity) are applied at several points in the criminal justice process in England and Wales and in the treatment of forensic patients. What would be the consequences of adopting incapacity principles here?

This question is complicated by the existence of many different categories of forensic patient. Such patients enter forensic care both on transfer from prison and directly from the criminal courts, and they enter it at many different points in the criminal trial process. Some are remanded to hospital prior to or during their trial; others have been found guilty at trial, or have been found not guilty by reason of insanity or unfit to stand trial. Some forensic patients can be returned to prison if their health improves; others cannot because they are not subject to a current prison sentence.

Generally speaking, under the law in Britain and Australasia, psychiatric treatment without consent of forensic patients (other than those remanded purely for assessment) is governed by the same principles as the treatment of patients committed under mental health legislation. That is, forensic patients who retain their capacity to consent do not usually enjoy the legal right to refuse psychiatric treatment, nor must their capacity be specifically assessed whenever treatment is proposed. They may usually be treated without their consent until fully discharged from involuntary status. How would the law handle the treatment of such patients in the future if the functions of the Mental Health Act 1983 were merged into a comprehensive treatment statute based on incapacity principles? Could forensic patients then be treated without their consent only when they lacked capacity to make specific treatment decisions, as is now the law in some Canadian provinces (Starson $v$. Swayze, 2003)? This is a particularly difficult question when forensic patients may not be under treatment primarily for their own benefit, but for the protection of others. Perhaps in a small category of forensic cases pure incapacity principles should be compromised, to respect the competing ethical imperative of reducing harm to others. We suggest that most legal issues concerning treatment of forensic patients could be resolved by applying the principles listed below.

(a) Any prisoner or forensic patient with capacity who consents to treatment may be treated voluntarily in an appropriate facility. Any sentence would continue to run.

(b) When forensic patients lack the capacity to make treatment decisions, their treatment without consent would be justified on the same basis as other incapacitated patients.

(c) When prisoners lack the capacity to consent to treatment, their transfer to hospital and treatment without consent would be authorised. If they regain capacity, treatment could continue only with their consent, with return to prison if they refused.

(d) In the case of those found not guilty by reason of insanity or unfit to stand trial, who cannot be sent to prison, their treatment without consent might be lawful even if they retained capacity, on the following conditions: they have been shown, on reliable evidence, to have committed the acts or omissions necessary to constitute a serious offence; they are suffering from a serious mental disorder that contributed significantly to that conduct; and an effective treatment can be offered that could reasonably be expected to reduce the risk of its recurrence. This would be a limited exception to pure incapacity principles, necessary to reduce the risk of harm to others.

(e) Upon a person's conviction for a serious criminal offence, an appropriate prison sentence would be imposed. Offenders who were found to lack capacity to consent to treatment at that time could still be directed to hospital for treatment, and during their time in hospital their prison sentence would run. If they regained capacity and refused treatment, however, they would be transferred to prison to continue their sentence. At the end of their sentence, if capacity was not regained, their involuntary 
treatment could continue as a civil patient.

Alternatively, a criminal court imposing a hospital order for treatment following a person's conviction could set a limiting term, proportionate to the seriousness of the offence, during which involuntary treatment would be lawful despite that person's capacity, on the same conditions as those stated above for those found not guilty by reason of insanity.

If these principles were followed, the consequences of applying incapacity criteria to the treatment of most forensic patients would not be unacceptable, nor would intolerable burdens be imposed on the forensic or prison systems.

Incapacity schemes respect the patient's autonomy but do not adequately address treatment of the incapacitated but objecting patient. Mental health legislation places less emphasis on autonomy, but clearly addresses emergency treatment, detention and involuntary treatment. The fusion of the two schemes into comprehensive legislation, which retains the strengths of both, can be readily envisaged. We have described the key principles and are confident that the details could be successfully addressed.

\section{ACKNOWLEDGEMENT}

We gratefully acknowledge the support of the New Zealand Law Foundation for this research.

\section{REFERENCES}

British Medical Association \& The Law Society (2004) Assessment of Mental Capacity (2nd edn). London: BMJ Books.

Cairns, R., Maddock, C., Buchanan, A., et al (2005) Reliability of mental capacity assessments in psychiatric in-patients. British Journal of Psychiatry, 187, 372-378.

Dawson, J. (1996) Psychopathology and civil commitment criteria. Medical Law Review, 4, 62-83.

Department of Health (2004) Draft Mental Health Bill. Cm 6305. London: TSO (The Stationery Office)

Grisso, T. \& Appelbaum, P. (1998) Assessing Competence to Consent to Treatment. New York: Oxford University Press.

Home Office \& Department of Health and Social Security (1975) Report of the Committee on Mentally

\section{CLINICAL IMPLICATIONS}

- A single statutory process based on incapacity principles could govern involuntary treatment of both psychiatric and general medical conditions.

- Intervention might be lawful at an earlier stage of illness than would be permitted in England and Wales under the Mental Health Act 1983.

- These proposals would reduce discrimination in the law against psychiatric patients and would apply consistent ethical principles across medical law.

\section{LIMITATIONS}

- These proposals have not been adopted as government policy in Britain despite their discussion during recent law reform debates.

- No research has been published on the reliability of capacity assessment in the emergency circumstances typical of civil commitment.

- More people with personality disorders who retain their capacity to consent to treatment might be imprisoned instead of receiving forensic care.

JOHN DAWSON, LLM, Faculty of Law, University of Otago, Dunedin, New Zealand; GEORGE SZMUKLER, MD, FRCPsych, Institute of Psychiatry, King's College London, UK

Correspondence: Professor John Dawson, Faculty of Law, University of Otago, PO Box 56, Dunedin, New Zealand. E-mail: john.dawson@stonebow.otago.ac.nz

(First received 23 November 2004, final revision II July 2005, accepted 3 October 2005)

Abnormal Offenders (the Butler Report). Cmnd 624. London: TSO (The Stationery Office).

Joint Committee on the Draft Mental Health Bill (2005) Report of the Joint Committee on the Draft Mental Health Bill. London: TSO (The Stationery Office).

Millan, B. (200I) New Directions. Report on the Review of the Mental Health (Scotland) Act 1984. Edinburgh:

Scottish Executive.

Peay, J. (1989) Tribunals on Trial: A Study of DecisionMaking under the Mental Health Act 1983. Oxford: Clarendon Press.

Peay, J. (2003) Decisions and Dilemmas: Working with Mental Health Law. Oxford: Hart.

Perkins, E. (2003) Decision-Making in Mental Health Review Tribunals. London: Policy Studies Institute.

Raymont, V., Bingley, W., Buchanan, A., et al (2004) Prevalence of mental incapacity in medical inpatients and associated risk factors: cross-sectional study. Lancet, 364, $1421-1427$.
Richardson, G. (1999) Review of the Mental Health Act 1983: Report of the Expert Committee. London: Department of Health.

Roth, L., Appelbaum, P., Sallee, R., et al (1982) The dilemma of denial in the assessment of competency to refuse treatment. American journal of Psychiatry, 139, 910-913.

United Nations (1966) International Covenant on Civil and Political Rights. Geneva: Office of the High Commissioner for Human Rights (http: // www.unhchr.ch/html/menu3/b/a_ccpr.htm)

R v. Bournewood Community and Mental Health NHS Trust, ex parte L [1998] 3 WLR 107.

HL v. The United Kingdom [2004] Application no. 45508/99 ECHR.

In re C (adult: refusal of medical treatment) [1994] I WLR 290.

Starson v. Swayze [2003] I SCR 722. (SCC). 